\title{
Influence of Titanium and Vanadium on the Hydrogen transport through amorphous alumina films
}

\author{
G. K. Pálsson ${ }^{\mathrm{a}}$, Y. T. Wang, D. Azofeifa ${ }^{\mathrm{b}}$, H. Raanaei ${ }^{\mathrm{a}, \mathrm{c}}$, M. Sahlberg ${ }^{\mathrm{d}}$, B. Hjörvarsson ${ }^{\mathrm{a}, *}$ \\ ${ }^{a}$ Department of Physics, Uppsala University, Box 530, S-751 21 Uppsala, Sweden \\ ${ }^{b}$ Centro de Investigación en Ciencia e Ingeniería de Materiales and Escuela de Física, Universidad de Costa Rica, San José, Costa Rica \\ ${ }^{c}$ Department of Physics, Persian Gulf University, Bushehr 75168, Iran \\ ${ }^{d}$ Department of Materials Chemistry, Uppsala University, Box 538, S-751 21 Uppsala, Sweden
}

\begin{abstract}
The influence of titanium and vanadium on the hydrogen transport rate through thin amorphous alumina films is addressed. Only small changes in the transport rate are observed when the $\mathrm{Al}_{2} \mathrm{O}_{3}$ are covered with titanium or vanadium. This is in stark contrast to results with a Pd overlayer, which enhances the transport by an order of magnitude. Similarly, when titanium is embedded into the alumina the transport rate is faster than for the covered case but still slower than the undoped reference. Embedding vanadium in the alumina does not yield an increase in uptake rate compared to the vanadium covered oxide layers. These results add to the understanding of the hydrogen uptake of oxidized metals, especially the alanates, where the addition of titanium has been found to significantly enhance the rate of hydrogen uptake. The current findings eliminate two possible routes for the catalysis of alanates by $\mathrm{Ti}$, namely dissociation and effective diffusion short-cuts formed by Ti. Finally, no photocatalytic enhancement was noticed on the titanium covered samples.
\end{abstract}

Key words: Thin films, Catalysis, Hydrogen absorbing materials, Ti, $\mathrm{NaAlH}_{4}$

\section{Introduction}

Solid state storage of hydrogen has the potential to become an important energy carrier in the hydrogen economy [1]. This is partly due to its high volumetric density and generally high reversibility and reproducibility of the hydride formation [2]. However, many metal hydrides suffer from poor gravimetric density and unfavorable enthalpies of formation [3]. One of the more interesting classes of materials with the potential to remedy these are the Al based hydrides such as $\mathrm{NaAlH}_{4}$ and $\mathrm{LiAlH}_{4}$. This class of hydrides, known as alanates, exhibit sufficiently high gravimetric storage density ( $5.5 \% \mathrm{wt}$. ideal) but suffer from slow uptake and release of hydrogen $[4,5,6,7,8]$. Another drawback of the alanates is the high enthalpy of formation.

The rate of hydrogen uptake and release appears to be accelerated by orders of magnitude by the addition of $\mathrm{Ti}$, $\mathrm{TiCl}_{3}$ and $\mathrm{TiFl}_{3}$ in alanates. The desorption temperatures have also been shown to be significantly lowered [9]. It was initially thought the reason for this was because the presence of titanium in the bulk of the particles destabilizes the hydride phase (i.e. lowers the enthalpy). However the consensus seems to be shifting, with an increasing body of

\footnotetext{
*Björgvin Hjörvarsson

Email addresses: bjorgvin.hjorvarsson@fysik.uu.se (B. Hjörvarsson)

$U R L$ : material.fysik.uu.se (B. Hjörvarsson)
}

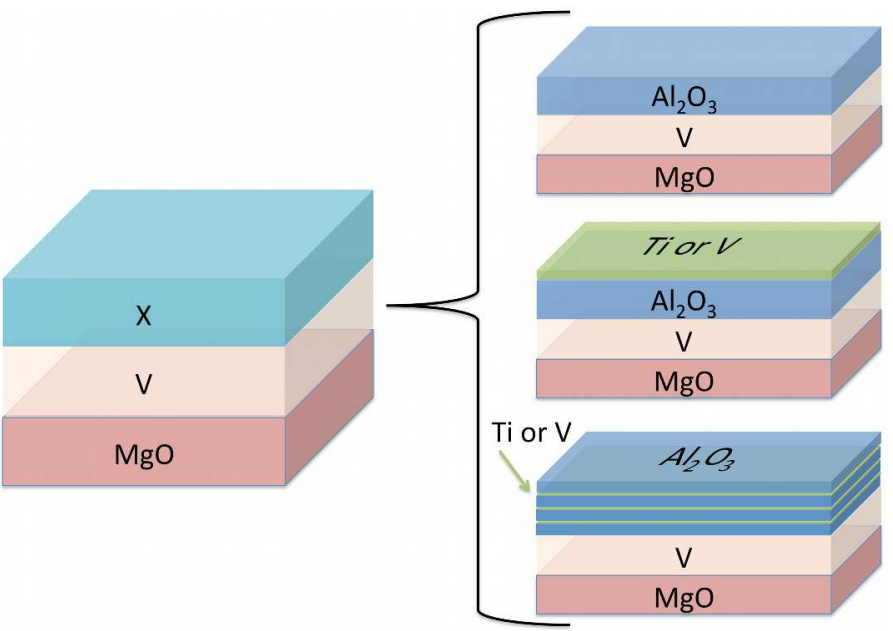

Figure 1: Schematic illustration of the different types of samples. On the left is the basic structure consisting of a MgO substrate and a vanadium layer. Three different cases are considered. The top sample is coated with alumina, the middle sample is coated with alumina and a layer of either vanadium or titanium and the final sample is grown by dosing $\mathrm{Ti}$ or $\mathrm{V}$ in between alumina layers. This is referred to as $\delta$-doping of the $\mathrm{Al}_{2} \mathrm{O}_{3}$ where the oxide and the dopant are grown as a multilayer. 
results $[10,7,11]$ are suggesting that the main part of the activating titanium is located at or near the surface of the alanate particles. Thus it appears likely that the titanium acts as a surface catalyst but the details of its role and function are still unclear.

Due to their high reactivity, the handling of alanates is normally restricted to glove boxes in an Ar atmosphere, where oxygen and water content are typically on the order of $0.1 \mathrm{ppm}$. Using simple arguments from the kinetic theory of gases $\left(P / \sqrt{2 \pi M k_{B} T}\right)$, this can be shown to roughly correspond to $30 \mathrm{ML}$ (monolayers) of contaminants impinging on the surface per second ( $0.1 \mathrm{ppm}$ of $\mathrm{H}_{2} \mathrm{O}$ in $1 \mathrm{~atm}$ of Ar at $293.15 \mathrm{~K}$ ). It is therefore clear that a self passivating oxide of $\mathrm{Al}_{2} \mathrm{O}_{3-\delta}$ is rapidly formed upon the unintentional exposure to oxygen and water. Thin oxide shells have indeed been observed in micrographs on $\mathrm{NaAlH}_{4}[12,13]$ and $\mathrm{LiAlH}_{4}$ [14] and with NMR on $\mathrm{NaAlH}_{4}[15]$.

The hydrogen flux through thin films of amorphous alumina have recently been investigated by Wang et al. [16], who observed an exponential decrease in flux with increasing alumina thickness, in the range 1-3 nm. When coating the films with $\mathrm{Pd}$, thereby providing atomic hydrogen to the $\mathrm{Pd} /$ alumina interface, the flux increased by an order of magnitude. This suggests that the transport of hydrogen through amorphous alumina is a surface dissociation limited process. Since the $\mathrm{Ti} / \mathrm{TiO}_{2}$ particles in the alanates have been confirmed to reside at or near the surface, this raises the question what effect it has on the hydrogen transport through the alumina oxide shells. Moreover, several other metal oxides such as $\mathrm{Nb}_{2} \mathrm{O}_{5}$ and $\mathrm{V}_{2} \mathrm{O}_{5}$ are known to enhance the hydrogen uptake of $\mathrm{MgO}$ coated Mg particles [17, 18, 19, 20].

It is unclear exactly how titanium enhances the uptake rate of the alanates and many propositions have been put forward in the literature, both based on experimental and theoretical considerations. The system is highly complex and many different processes could be involved, including diffusion, dissociation, $\mathrm{AlTi}_{3}$ cluster formation [15], et cetera. In this work we use a model system to address two of the possible processes for the enhanced rate of hydrogen uptake through thin oxide layers. Firstly, we address the influence of coating thin alumina with titanium and vanadium on the dissociation rate of hydrogen. Secondly we examine the role played by titanium and vanadium within the oxide layer on the transport rate. The sample structures used for the experiments are illustrated in Fig. 1. The rate of the hydrogen transport through the oxide layers was determined from the observed changes in the hydrogen concentration in a single crystal vanadium (001) layer, grown on a $\mathrm{MgO}$ (001) substrate.

\section{Experimental}

\subsection{Sample growth}

The samples were grown using magnetron sputtering in an Ultra High Vacuum (UHV) environment. The base pressure of the chamber is below $5 \times 10^{-10}$ Torr and the operating pressure of the sputtering gas (Ar) with a purity of $99.9999 \%$, was kept at $2.67 \times 10^{-3}$ mbar during growth. The vanadium, $\mathrm{Al}_{2} \mathrm{O}_{3}$ and titanium deposition rates were determined to be $0.03,0.003$ and $0.01 \mathrm{~nm} / \mathrm{s}$ respectively, using $\mathrm{X}$-ray reflectivity measurements from a calibration sample. Both vanadium (99.7\%) and titanium $(99.7 \%)$ were deposited using a dc source whereas the $\mathrm{Al}_{2} \mathrm{O}_{3}$ was deposited at room temperature using an $\mathrm{Al}_{2} \mathrm{O}_{3}$ target $(99.9 \%)$ and $\mathrm{rf}$ sputtering. No additional oxygen was introduced into the chamber during the oxide growth.

All the samples were grown on a $\mathrm{MgO}$ (001) substrates, starting with vanadium (001) layers with a nominal thickness of $10 \mathrm{~nm}$. The vanadium layers were grown at $600 \mathrm{~K}$, resulting in an epitaxial growth of vanadium on the $\mathrm{MgO}$ (001) single crystal substrates. All the other layers were grown at temperatures around $300 \mathrm{~K}$. The samples grown for these studies can be divided into 3 categories, namely the reference sample and those containing titanium and vanadium as the added element. Hereafter we refer to these samples as the reference, the titanium and the vanadium series. The reference sample consists of nominally $5 \mathrm{~nm}$ thick alumina layer covering the underlying vanadium film, as illustrated in top right panel in Fig. 1.

The titanium series was based on two different distributions of Ti: a single layer with a nominal thickness of $0.8 \mathrm{~nm}$ titanium covering the alumina layer, and distributed within the alumina layer (titanium doped). The distribution of titanium in the alumina layer was accomplished by depositing 10 sub-monolayer thick titanium layers $(0.08 \mathrm{~nm})$, as illustrated in Fig. 1. We refer to this type of deposition as $\delta$-doping. The thickness of the outermost alumina layer was $0.36 \mathrm{~nm}$.

The vanadium series consisted of three samples. Two samples were covered with 0.2 and $0.8 \mathrm{~nm}$ vanadium respectively and the third sample was grown by depositing $0.8 \mathrm{~nm}$ vanadium inside the $\mathrm{Al}_{2} \mathrm{O}_{3}$ by $\delta$-doping. The multilayer was capped by a final layer of $0.36 \mathrm{~nm}$ of $\mathrm{Al}_{2} \mathrm{O}_{3}$.

\subsection{X-ray reflectivity and diffraction}

Structural analysis were performed with x-ray diffraction (XRD) and x-ray reflectivity (XRR) using a Siemens D5000 diffractometer with $\operatorname{CuK}_{\alpha}(\lambda=0.15418 \mathrm{~nm})$ in a standard Bragg-Brentano geometry. An open source software package called GenX [21] was used for the reflectivity refinement. The program uses a genetic algorithm for the fitting and the Parratt [22] formalism for the model calculation. The software takes into account absorption and multiple reflections as well as instrumental corrections and allows the determination of all the layer thicknesses, and an estimate of the interfacial roughnesses by assuming a Gaussian height fluctuation.

\subsection{X-ray photo-electron spectroscopy}

The composition and chemical state of the included elements were analyzed ex-situ with X-ray photoelectron 
Table 1: The Table summarizes the results from the XRR simula-

\begin{tabular}{cccccc} 
tions. & $\begin{array}{c}T_{\mathrm{V}}{ }^{a} \\
{[\mathrm{~nm}]}\end{array}$ & $\begin{array}{c}T_{\mathrm{Al}_{2} \mathrm{O}_{3}}[\mathrm{~nm}] \\
\text { Sample }\end{array}$ & $\begin{array}{c}T_{\mathrm{cov}}{ }^{b} \\
{[\mathrm{~nm}]}\end{array}$ & $\begin{array}{c}\sigma_{\mathrm{V}}{ }^{c} \\
{[\mathrm{~nm}]}\end{array}$ & $\begin{array}{c}\sigma_{\mathrm{Al}_{2} \mathrm{O}_{3}}{ }^{d} \\
{[\mathrm{~nm}]}\end{array}$ \\
\hline Reference & 10.9 & 5.4 & - & 0.8 & 1.0 \\
Ti covered & 9.8 & 6.1 & 1.9 & 0.6 & 0.6 \\
Ti doped & 8.8 & 5.9 & - & 0.4 & 0.9 \\
V covered & 10.9 & 5.1 & 1.0 & 0.6 & 0.2 \\
\hline \hline
\end{tabular}

${ }^{a}$ vanadium layer thickness

${ }^{b}$ cover layer thickness if any

${ }^{c}$ vanadium roughness

${ }^{d} \mathrm{Al}_{2} \mathrm{O}_{3}$ roughness

spectroscopy (XPS) using a PHI Quantum 2000 spectrometer, with monochromatized $\mathrm{AlK}_{\alpha}$ radiation. The samples were introduced into the chamber and analyzed without any surface cleaning. Binding energy calibration was performed using the $\mathrm{C} 1 \mathrm{~s}$ peak of the surface carbon contamination as a reference. The value of the $\mathrm{C} 1 \mathrm{~s}$ peak was taken at $284.8 \mathrm{eV}$. All samples showed some displacement in the peak positions due to charging.

\subsection{Hydrogen flux measurements}

The instrument consists of a UHV compatible chamber with residual hydrogen pressures below $10^{-8}$ mbar and gases other than hydrogen below $5 \times 10^{-10}$ mbar as measured with a Residual Gas Analyser (RGA). The resistance changes were measured with a four-point, current reversal technique and the temperature was measured with a Chromel-Alumel thermocouple in direct contact with the sample surface. The hydrogen absorption curve was recorded by monitoring the resistance changes after rapidly filling the chamber with a certain pressure of highly purified $\mathrm{H}_{2}$ by opening a pneumatic valve to an adjacent hydrogen reservoir. The changes in resistance were subsequently converted into hydrogen concentration using the unloaded and fully loaded values as a reference [16]. To obtain the initial flux $(F)$ through the oxide, the slope at initial uptake $(s)$ was determined from the concentration vs. time curve and the flux calculated according to:

$$
F=N_{\mathrm{V}} d_{\mathrm{V}}
$$

where $N_{\mathrm{V}}$ is the number of $\mathrm{V}$ atoms per $\mathrm{cm}^{3}$ and $d_{\mathrm{V}}$ is the thickness of the vanadium layer.

\section{Results}

\subsection{Structural characterization}

The diffraction data confirmed the crystallinity and orientation of the underlying vanadium layers and the substrate, whereas no other peaks were observed in the range 20-90 degrees in 20. A single peak was observed at $60.16(2)$ degrees with a FWHM of 0.99 degrees as expected from the intended vanadium thickness. The peak was assigned

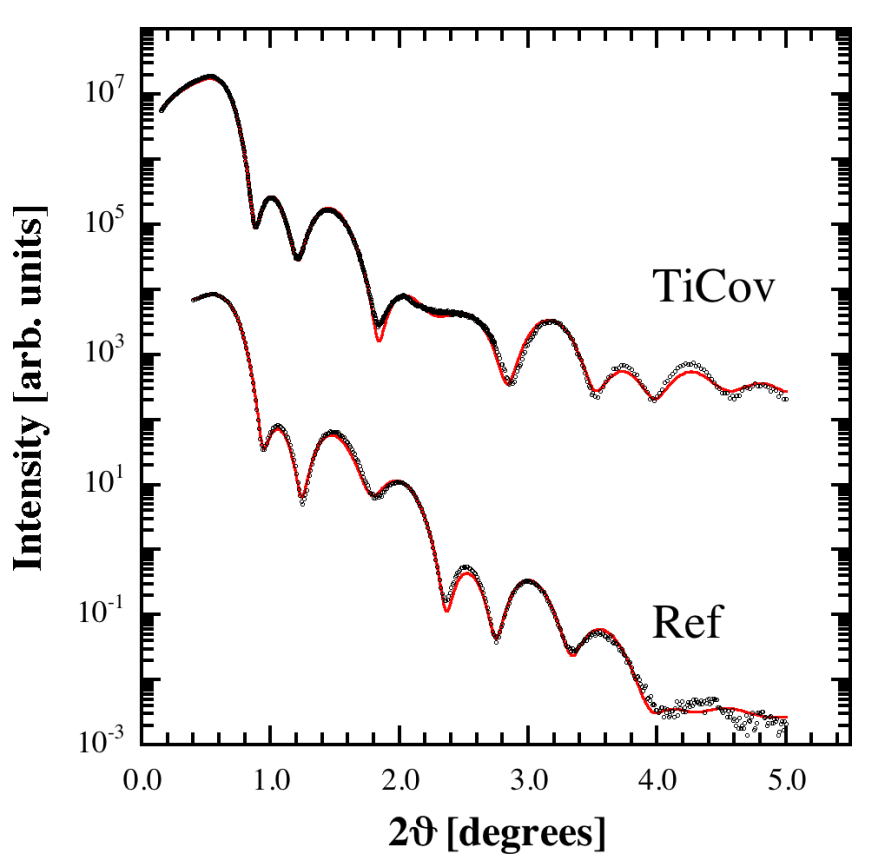

Figure 2: Two reflectivity curves of the reference sample and the titanium covered sample are shown measured at room temperature without hydrogen. The red (on-line) solid line is a simulation using the GenX package. The numerical values can be found in Table 1 .

to the (002) planes of vanadium. Weak Laue oscillations are visible which are expected for a single-crystal film of finite thickness. However the matching of vanadium to $\mathrm{MgO}$ is not ideal and the mosaicity was determined to be 0.5 degrees by performing a rocking scan over the (002) peak.

XRR was used to determine the individual thicknesses and the thickness variation of the layers. The thicknesses of the vanadium layers were used in the calculation of the hydrogen flux. Table 1 includes the thicknesses and the thickness variation (roughness) of the samples considered here. Figure 2 shows two XRR patterns belonging to the titanium covered sample and the reference with the corresponding simulated curves. The data has been scaled vertically for clarity and gives a representative view of the quality of the fitting.

\subsection{Oxidation states}

XPS was used to determine the chemical state of the metal oxides. Firstly, XPS was performed on the reference samples which revealed that there was no detectable elemental $\mathrm{Al}$ in the oxide and no detectable vanadium oxide in the underlying vanadium film. Note the $\mathrm{Al} 2 \mathrm{p}$ peak at $74 \mathrm{eV}$, a value typical for $\mathrm{Al}_{2} \mathrm{O}_{3}$ [23], and the characteristic tail of the elemental vanadium $2 \mathrm{p}_{3 / 2}$ peak at $512.4 \mathrm{eV}$ in Fig. 3.2. To obtain information about the interface state of the vanadium layers, we performed in-situ sputtering while following the chemical state using XPS. From these measurements we identified slightly oxidized vanadium at the boundary between the $\mathrm{Al}_{2} \mathrm{O}_{3}$ and the vanadium layers. 


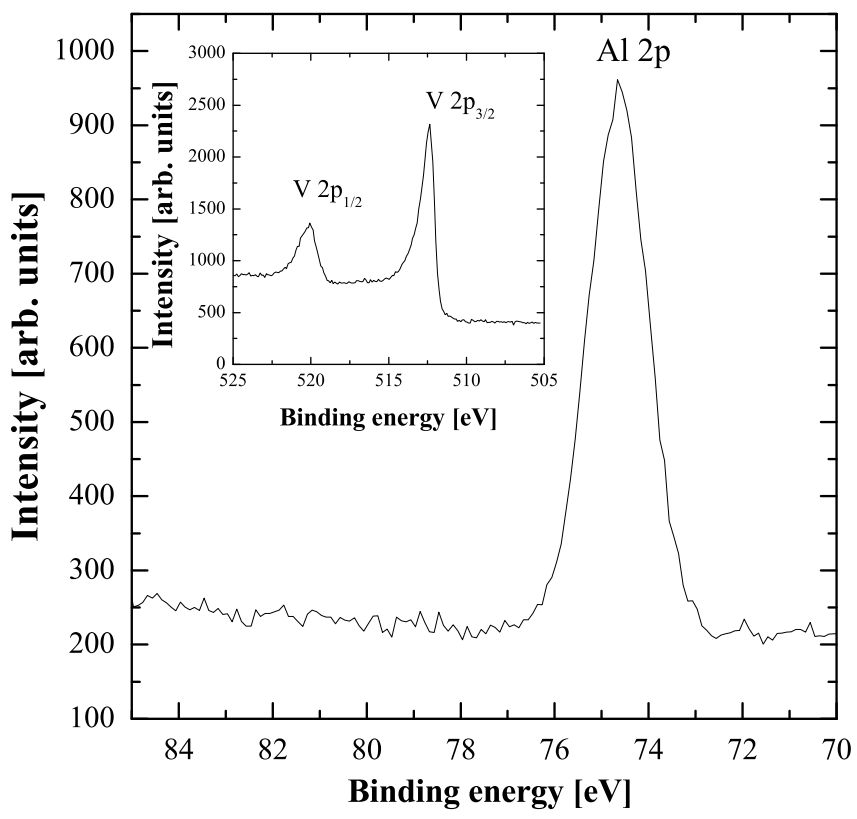

Figure 3: XPS data from the reference sample showing the $\mathrm{Al}_{2} \mathrm{O}_{3}$ peak and the metallic vanadium $2 \mathrm{p}_{3 / 2}$ and vanadium $2 \mathrm{p}_{1 / 2}$ peaks in the inset. The XPS was recorded ex-situ without hydrogen.

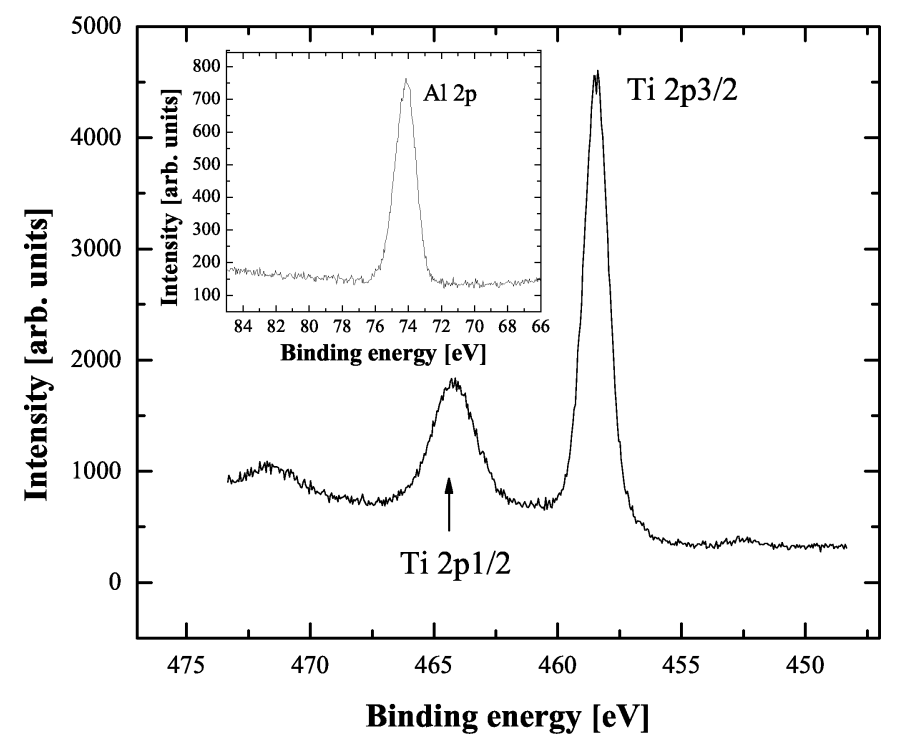

Figure 4: XPS data from the titanium covered sample showing the $\mathrm{TiO}_{2} 2 \mathrm{p}_{3 / 2}$ peak and a weak peak at around $453.3 \mathrm{eV}$. The weak peak could be In surface contamination or elemental titanium. The inset shows the $\mathrm{Al}_{2} \mathrm{O}_{3} 2 \mathrm{p}$ peak.
The oxidation states of both the titanium covered and titanium doped samples were confirmed to be $\mathrm{TiO}_{2}$. The titanium $2 \mathrm{p}_{3 / 2}$ peak was observed at $458.4 \mathrm{eV}$, a value typical for $\mathrm{TiO}_{2}$ or other titanium 4+ or 4- compounds [23]. It is possible that the doped samples contain a small contribution from elemental titanium as can be judged from the small peak at $453.3 \mathrm{eV}$ as seen in in Fig. 4. However, this peak for elemental titanium overlaps with the surface contamination In $3 \mathrm{~d} 3 / 5$ peak and thus it is difficult to unequivocally ascertain the origin of the peak. For the covered samples titanium existed exclusively as $\mathrm{TiO}_{2}$, as seen in Fig. 4. When comparing the $\mathrm{Al}$ peaks for the doped and covered titanium samples, it can be seen that there is a slight shift to lower energies for the doped sample, supporting the view that elemental titanium resides inside the oxide. However, this shift is small relative to the titanium shift, and might be an effect of charging or surface contamination.

For the vanadium doped and covered samples, vanadium was found exclusively in its oxide state $\mathrm{V}_{2} \mathrm{O}_{5}$ at the surface of the film, with the $\mathrm{V} 2 \mathrm{p} 3 / 2$ peak at $517.0 \mathrm{eV}$. This is also consistent with the electron density obtained from XRR. No conclusive results were obtained on the vanadium doped films, due to drift caused by the charge built up at the sample surface during the measurements.

\subsection{Flux measurements}

In Fig. 5 three absorption curves obtained at $473 \mathrm{~K}$ and 130 mbar corresponding to the reference, titanium covered and titanium doped are shown. The slope at initial uptake is taken as a measure of the flux through the film since it is assumed that the resistance change originates in the vanadium layers and not from the oxide. The Fig. shows that the initial slope is steepest for the reference sample.

Figure 6 shows the calculated flux as a function of pressure for three of the samples, reference, titanium covered and titanium doped. The three panels correspond to 523, 473 and $423 \mathrm{~K}$ respectively. The solid lines are linear least squares fit to the data. Since the axes are both logarithmic the slope corresponds to the power of the pressure, $P$, and the intercept gives the pre factor. For titanium covered and titanium doped samples, the slopes are close to 0.5 and do not change noticeably with temperature. For the reference sample the slope changes from 0.1-0.4 with temperature. Although the uncertainties in these values are large, we believe it is reasonable to conclude that the slopes change for the reference sample, but not for the others. The data consistently shows that the reference sample exhibits the highest flux, followed by the doped and the covered. All measurements were performed under dark conditions. We performed separate uptake measurements under illumination of visible and UV (6700 K) but found no evidence of photon induced enhancement of the uptake rate. An Arrhenius analysis was performed on the results and the deduced activation energies are listed in Table 2.

To put these results into context with previous data Fig. 7 displays a plot of the flux against oxide thickness 


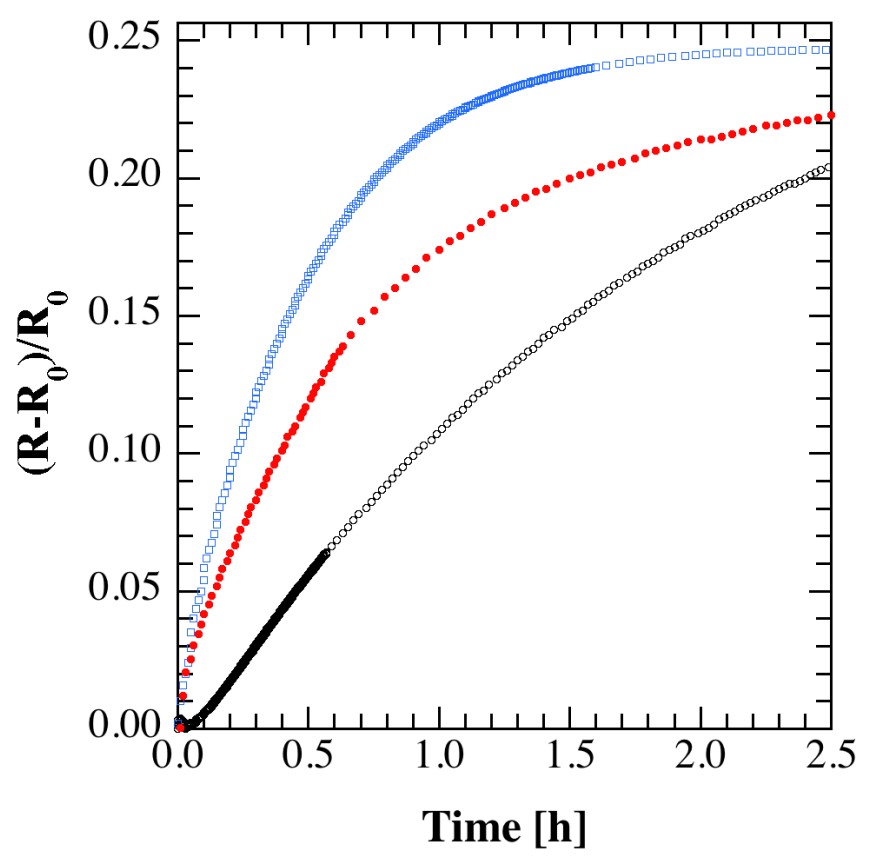

Figure 5: The resistance changes as the absorption process develops with time for three samples at $473 \mathrm{~K}$ and $130 \mathrm{mbar}$. The top curve corresponds to the reference sample, the middle to the the doped and the lowest to the covered titanium series. The slope at time approaching zero is taken as a measure of the flux through the sample since only the underlying vanadium is expected to change upon absorption. It can be seen directly from this raw data that the flux through the oxide barrier is highest without doping. $R_{0}$ is the resistance without hydrogen.
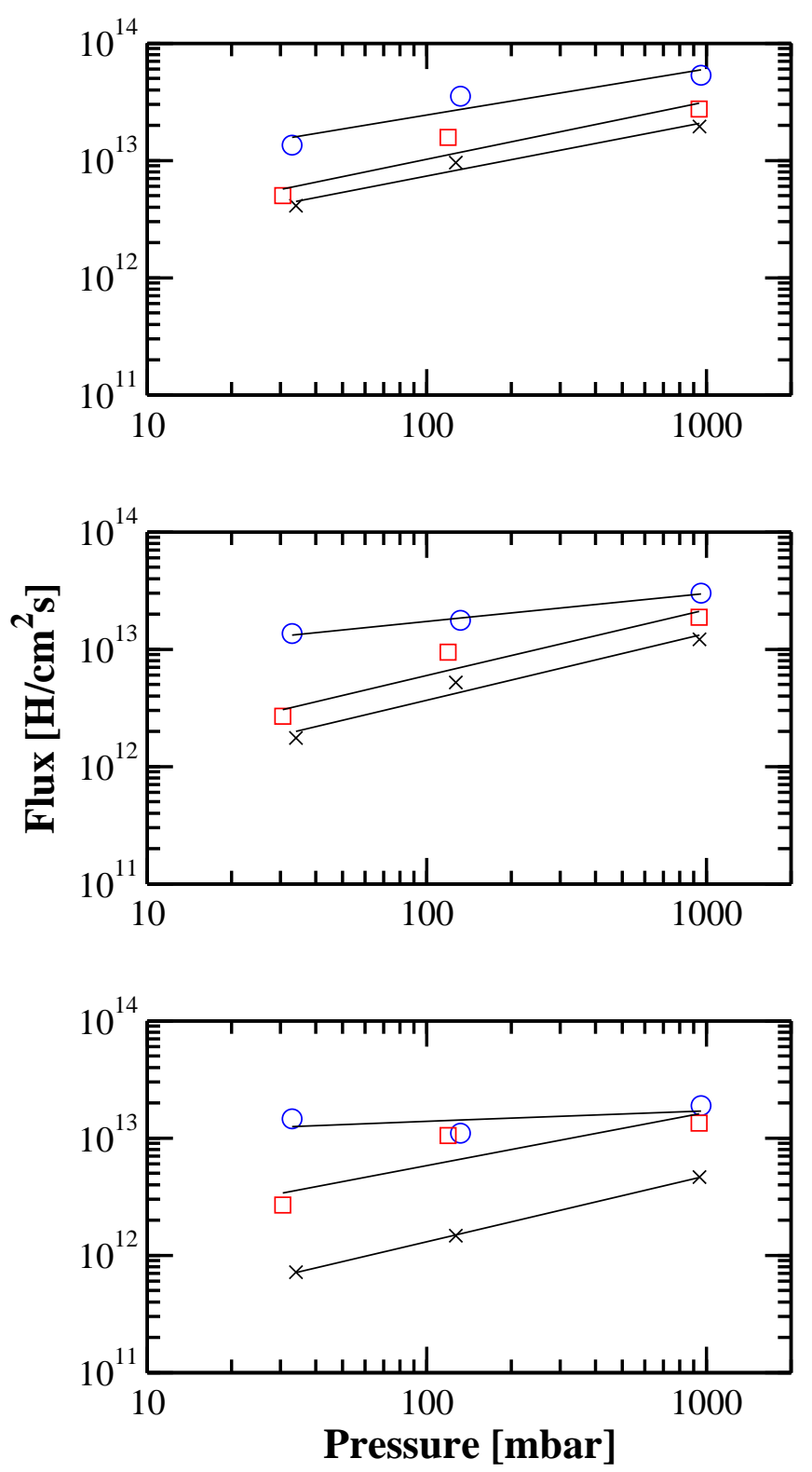

Figure 6: Hydrogen flux as a function of pressure for three samples at 523, 473 and $423 \mathrm{~K}$ from top to bottom. The blue circles represent the reference sample, the red squares correspond to the titanium doped sample and the black crosses indicates the sample with a $\mathrm{TiO}_{2}$ overlayer. 


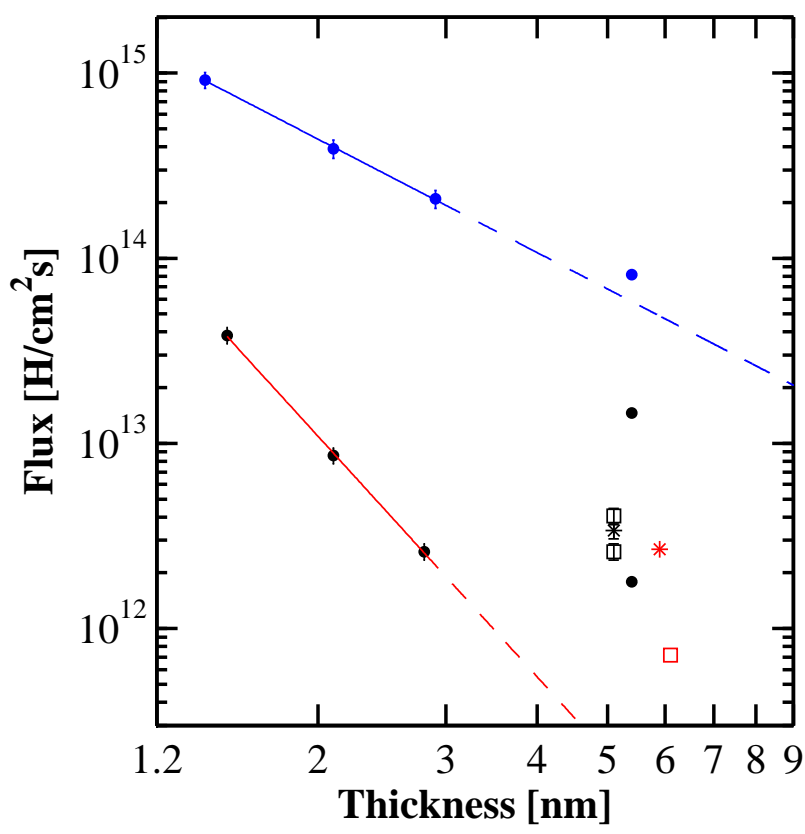

Figure 7: Flux as a function of oxide thickness at $423 \mathrm{~K}$ and 30 mbar. The Fig. consists of new data with oxide thickness around $5 \mathrm{~nm}$ and data from Wang et al. [16] with thicknesses 1-3 $\mathrm{nm}$. The solid line is a best fit to a power law and the dash-dotted line is an extrapolation. The filled blue circles are the results from samples capped with 5 $\mathrm{nm}$ of Pd and the filled black circles refer to the reference samples. The red star is the result from the titanium doped sample and the red square the titanium covered sample. The black star and square represent the results from the vanadium doped and capped samples respectively.
Table 2: Activation energies for the different samples at the different pressures. Uncertainties are estimates at $67 \%$ confidence.

\begin{tabular}{cccc}
\hline \hline Sample & $\begin{array}{c}33 \text { mbar } \\
{[\mathrm{eV}]}\end{array}$ & $\begin{array}{c}132 \text { mbar } \\
{[\mathrm{eV}]}\end{array}$ & $\begin{array}{c}954 \text { mbar } \\
{[\mathrm{eV}]}\end{array}$ \\
\hline Reference & - & $0.22(7)$ & $0.20(4)$ \\
Ti covered & $0.33(3)$ & $0.36(8)$ & $0.28(6)$ \\
Ti doped & - & - & $0.14(2)$ \\
\hline \hline
\end{tabular}

at $423 \mathrm{~K}$ and approximately 30 mbar. The data measured here correspond to thicknesses around $5 \mathrm{~nm}$ whereas older data measured by Wang et al. [16] were measured on samples with 1-3 nm thicknesses, with and without a Pd capping (blue and black points, respectively). From Wang's data it is possible to extrapolate a thickness dependence on the flux which is represented by the broken lines in Fig. 7. The solid lines are best fits to a power law. Noteworthy is that the flux from the reference samples are much higher than the extrapolated values from Wang (solid black circles). The two reference points at $5.1 \mathrm{~nm}$ come from two copies of the same sample structure. A third copy of the reference was capped with $\mathrm{Pd}$ and subsequently measured, yielding a flux that is close to what is expected from the extrapolation (blue solid circle). Judging from Fig. 7 it seems clear that doping or covering alumina with titanium or vanadium does not yield a big improvement of the initial flux compared to the scattering of the results of the reference. It is concluded that these two metal oxides possess a lower catalytic activity than $\mathrm{Pd}$.

\section{Discussion and Conclusions}

The atomic fraction of $\mathrm{H}$ on the surface, $\theta$, varies linearly with pressure, $P$, for molecular adsorption and as the $\sqrt{P}$ for dissociative processes, as predicted by Langmuir. Later, Davenport et al. [24] concluded that if the barrier between the surface and the interior is large, the initial uptake rate in the bulk should vary like the square root of the pressure and exponentially with temperature. However, if the surface barrier is very small, the initial uptake rate is expected to vary linearly with pressure and to be nearly independent of temperature. These conclusions can be used as a rough guide for qualitative judgement of the different rate limiting steps in the current context.

It seems clear that the reference sample does not exhibit a $\sqrt{P}$ dependence on the initial flux, which leads us to conclude that dissociation is not the rate-limiting step, which is the same conclusion as reached by Wang et. al. The transport of hydrogen through the oxide film appears therefore to be the rate limiting step for $\mathrm{Al}_{2} \mathrm{O}_{3}$ layers.

For both sample types in the titanium series, the uptake rate follows approximately $\sqrt{P}$. Furthermore, neither the addition of $\mathrm{TiO}_{2}$ on the surface nor the addition of titanium in the $\mathrm{Al}_{2} \mathrm{O}_{3}$ layer appear to improve the uptake rate. The addition of titanium even appears to inhibit the surface dissociation, which is surprising considering the 
effect of titanium doping on the hydrogen uptake of the alanates. Although the reduction of the reaction rate may be understood by considering that the titanium is in an oxide form, this would require the transport rate of hydrogen through the titanium oxide to be comparable or slower than its transport through the $\mathrm{Al}_{2} \mathrm{O}_{3}$ layers.

The transport through the oxide layer can be explained by a high concentration of defects throughout the alumina with associated dangling bonds which forms effective diffusion paths as well as dissociation sites in the surface region. The covered sample also exhibits increased activation energy, which might be an activation barrier for dissociation. For the titanium doped the activation energy seems lower than the reference and is not the reason for the reduced uptake rate. It is not understood how a lower activation energy can result in a slower uptake, uncertainties arising from parallel pathways of dissociation and transport through the oxide layers cannot be excluded at this stage. In conclusion, a reduction in the initial uptake rate is observed both when covering thin $\mathrm{Al}_{2} \mathrm{O}_{3}$ with titanium (vanadium) and when introducing titanium (vanadium) as an additional element in the oxide. When covering the alumina films with titanium (vanadium), they readily oxidise as a consequence of the exposure to ambient atmosphere. The oxide film therefore consists of two distinct layers: an inner $\mathrm{Al}_{2} \mathrm{O}_{3}$ layer and an outer $\mathrm{TiO}_{2}\left(\mathrm{~V}_{2} \mathrm{O}_{5}\right)$ layer. A continuous $\mathrm{TiO}_{2}\left(\mathrm{~V}_{2} \mathrm{O}_{5}\right)$ layer does not improve the hydrogen uptake. Furthermore, randomly distributed titanium (vanadium) does not appear to contribute to an increased surface activity or an increased transport rate through oxide films, either. The presence of element segregation and formation of small grains is highly likely in random small grain structures. Thus, it is conceivable the increased activity in the alanates is caused by the formation of small active clusters with grain boundary diffusion as a main transport of hydrogen. To clarify this possibility one needs to mimic the structures obtained in the doping process, which most likely involves large concentration gradients of the constituents.

\section{Acknowledgements}

Dr. Marcellini and Dr. Liebig are gratefully acknowledged for assistance with growth of $\mathrm{Pd}$ capping of the reference sample.

\section{References}

[1] J. Ritter, Mater. Today 6 (2003) 18-23.

[2] A. Züttel, Mater. Today 6 (2003) 24-33.

[3] L. Schlapbach, A. Züttel, Nature 414 (2001) 353-358.

[4] B. Bogdanovic, M. Schwickardi, J. Alloy. Compd. 253 (1997) $1-9$.

[5] B. Bogdanovic, M. Felderhoff, S. Kaskel, A. Pommerin, K. Schlichte, F. Schuth, Adv. Mater. 15 (2003) 1012-1015.

[6] R. Gremaud, A. Borgschulte, W. Lohstroh, H. Schreuders, A. Züttel, B. Dam, R. Griessen, J. Alloy. Compd. 404 (2005) $775-778$.
[7] J. Iñiguez, T. Yildirim, J Phys.: Condens. Mater. 19 (2007) 176007.

[8] P. Wang, X. Kang, H. Cheng, J. Appl. Phys. 98 (2005) 0749051-074905-5.

[9] K. Gross, G. Thomas, C. Jensen, J. Alloy. Compd. 330-332 (2002) $683-90$.

[10] C. Qiu, S. M. Opalka, O. M. Lovvik, G. B. Olson, CALPHAD 32 (4) (2008) 624-636.

[11] J. Graetz, J. Reilly, J. Johnson, A. Ignatov, T. Tyson, Appl. Phys. Lett. 85 (2004) 500.

[12] G. Thomas, K. Gross, N. Yang, C. Jensen, J. Alloy. Compd. 330 (2002) 702-707.

[13] C. Andrei, J. Walmsley, H. Brinks, R. Holmestad, S. Srinivasan, C. Jensen, B. Hauback, Appl. Phys. A 80 (2005) 709-715.

[14] C. Andrei, J. Walmsley, H. Brinks, R. Holmestad, D. Blanchard, B. Hauback, G. Botton, J. Phys. Chem. B 109 (2005) 43504356.

[15] J. Herberg, R. Maxwell, E. Majzoub, J. Alloy. Compd. 417 (2006) 39-44.

[16] Y. Wang, G. K. Pálsson, H. Raanaei, B. Hjorvarsson, J. Alloy. Compd. 464 (2008) L13-L16.

[17] G. Barkhordarian, T. Klassen, R. Bormann, Scripta Mater. 49 (2003) 213-217.

[18] G. Barkhordarian, T. Klassen, R. Bormann, J. Alloy. Compd. 364 (2004) 242-246.

[19] W. Oelerich, T. Klassen, R. Bormann, J. Alloy. Compd. 322 (2001) $5-9$.

[20] W. Oelerich, T. Klassen, R. Bormann, J. Alloy. Compd. 315 (2001) $237-42$.

[21] M. Björck, G. Andersson, J. Appl. Cryst. 40 (2007) 1174-1178.

[22] L. Parratt, Phys. Rev. 95 (1954) 359-369.

[23] G. R. Muilenberg (Ed.), Handbook of X-Ray Photoelectron Spectroscopy, Perkin-Elmer Corporation, Physical Electronics Division, Eden Prairie, 1979.

[24] J. Davenport, G. Dienes, R. Johnson, Phys. Rev. B 25 (1982) $2165-2174$. 